\title{
Estágio supervisionado: experiências e aprendizados por meio da atuação em sala de aula
}

\section{Supervised internship: experiences and learning by means of classroom practice}

\author{
Samara Côra Spadeto ${ }^{1}$ \\ Moyanne André de Amorim Leal2 \\ Selma Lúcia de Assis Pereira ${ }^{3}$
}

\begin{abstract}
Resumo
O presente relato de experiência refere-se à disciplina de Estágio Supervisionado II - anos finais do ensino fundamental do curso de graduação em Licenciatura em Letras/Português do Instituto Federal do Espírito Santo, campus Venda Nova do Imigrante - ES - e se constitui em uma síntese das observações e regência de sala de aula ocorridas durante o período de março a julho de 2019. 0 estágio supervisionado tem como objetivo nos possibilitar uma aproximação entre as teorias aprendidas no curso com a prática na sala de aula da escola (PIMENTA; LIMA, 2012). Dessa forma, a proposta trabalhada para a regência compartilhada foi com gêneros textuais, especificamente o gênero diário, por meio da sequência didática (DOLZ; SCHNEUWLY, 2011). Como resultado, percebemos, com as atividades desenvolvidas com os estudantes, uma aproximação significativa da teoria com a prática docente, por meio da observação, da coparticipação e, principalmente, da regência em sala de aula. 0 período de estágio revelou-se enriquecedor e desafiador, propiciando a aplicação de métodos de ensino eficazes, contribuindo para formação do aluno e corroborando nossa jornada de formação.
\end{abstract}

Palavras-chave: Estágio supervisionado. Formação docente. Sala de aula.

\section{Abstract}

The present experience report refers to the discipline of Supervised Internship II - final years of undergraduate degree in Language and Literature/Portuguese at the Federal Institute of Espírito Santo, Venda Nova do Imigrante campus - ES, and constitutes a synthesis of the observations and classroom conducting during the period from March to July 2019. The Supervised Internship aims to enable an approximation between the theories learned in the course and the practice in the school classroom, as postulated by Pimenta and Lima (2012). Thus, we proposed to work with textual genres as shared classroom conducting, specifically the diary, through the didactic sequence (DOLZ; SCHNEUWLY, 2011). As a result, by observing the activities developed with the students, we saw a significant approximation between theory and teaching practice, through observation, co-participation and, mainly, through the classroom conducting. The internship period proved to be enriching and challenging, enabling the application of effective teaching methods, contributing to student training and corroborating our training journey.

Keywords: Supervised internship. Teacher training. Classroom.

\footnotetext{
1 Graduanda do $8^{\circ}$ período do Curso de Licenciatura em Letras - Português. Instituto Federal do Espírito Santo, Campus Venda Nova do Imigrante, Espírito Santo, Brasil. Orcid: https://orcid.org/0000-0002-2676-2463. E-mail: samaraspadeto@hotmail.com

${ }^{2}$ Graduanda do $8^{\circ}$ período do Curso de Licenciatura em Letras - Português. Instituto Federal do Espírito Santo, Campus Venda Nova do Imigrante, Espírito Santo, Brasil. Orcid: https://orcid.org/0000-0002-6264-2450. E-mail: moyanneamorim@gmail.com

${ }^{3}$ Mestra em Educação, Universidade Federal do Espírito Santo. Instituto Federal do Espírito Santo, Campus Venda Nova do Imigrante, Espírito Santo, Brasil. Orcid https://orcid.org/0000-0002-1853-8920. E-mail: selma.pereira@ifes.edu.br
} 


\section{Introdução}

A experiência aqui relatada refere-se ao cumprimento do primeiro estágio supervisionado, no ensino fundamental, pelas turmas finais do curso de Licenciatura em Letras Português, do Instituto Federal do Espírito Santo - Campus Venda do Imigrante, Espírito Santo, Brasil.

O presente relato foi elaborado a partir das experiências vivenciadas na Escola Estadual de Ensino Fundamental Domingos Perim, mais precisamente nas turmas de sexto ano e na disciplina de Língua Portuguesa. Este relato mostra-se pertinente na medida em que nós, enquanto docentes em formação, adotamos essa nova vivência como propulsora de novos aprendizados, reflexões, mudanças e desafios a serem sempre superados. Além disso, o desenvolvimento das aulas destinadas às turmas foi planejado a partir de estratégias facilitadoras do aprendizado e, portanto, podem ser utilizadas como referência em outras áreas do saber, como História, Geografia e Arte.

\section{Breve contextualização do estágio supervisionado na instituição pesquisada}

Consideramos o estágio supervisionado na formação inicial muito importante para que o futuro docente possa conhecer, interagir e vivenciar as múltiplas realidades que 0 contexto social-culturalpedagógico assume. Dessa forma, nos baseamos nas diretrizes pautadas para esta finalidade como a Lei № 11.788, de 25 de setembro de 2008, que dispõe sobre o estágio de estudantes e estabelece que:

\footnotetext{
Art. $1^{\circ}$ Estágio é ato educativo escolar supervisionado, desenvolvido no ambiente de trabalho, que visa à preparação para o trabalho produtivo de educandos que estejam frequentando 0 ensino regular em instituições de educação superior, de educação profissional, de ensino médio, da educação especial e dos anos finais do ensino fundamental, na modalidade profissional da educação de jovens e adultos.
}

Além disso, pautamo-nos na Resolução CNE/CP nº 2, de 20 de dezembro de 2019, que define as Diretrizes Curriculares Nacionais para a Formação Inicial de Professores para a Educação Básica e institui a Base Nacional Comum para a Formação Inicial de Professores da Educação Básica (BNCFormação). Neste documento oficial, verifica-se a centralidade da prática por meio de estágios que enfoquem o planejamento, a regência e a avaliação de aula, sob a mentoria de professores ou coordenadores experientes da escola campo do estágio, de acordo com o Projeto Pedagógico do Curso (PPC) em seu Art. 7, inciso VIII. 
O presente relato está consonância também com a Resolução do Conselho Superior $n^{0} 58 / 2018$, de 17 de dezembro de 2018, que regulamenta os estágios dos alunos da Educação Profissional Técnica de Nível Médio e da Educação Superior do Instituto Federal de Educação, Ciência e Tecnologia do Espírito Santo (IFES), estabelecendo em seu art. $2^{\circ}$ o seguinte:

\footnotetext{
O estágio é considerado um ato educativo escolar supervisionado, desenvolvido no ambiente de trabalho, que visa à preparação para trabalho produtivo de educandos que estejam frequentando o ensino regular na Educação Profissional Técnica de Nível Médio e na Educação Superior, oferecido pelo Ifes nas modalidades presencial e a distância.

$\S 1^{\circ} \mathrm{O}$ estágio faz parte do projeto pedagógico do curso, além de integrar o itinerário formativo do educando.

$\S 2^{\circ} 0$ estágio visa ao aprendizado de competências próprias da atividade profissional e à contextualização curricular, promovendo:

I. o relacionamento dos conteúdos e contextos para dar significado ao aprendizado;

II. a integração à vivência e à prática profissional ao longo do curso;

III. a aprendizagem social, profissional e cultural para o desenvolvimento do educando para a vida cidadã e para o trabalho;

IV. a participação em situações reais de vida e de trabalho em seu meio;

V. o conhecimento dos ambientes profissionais;

$\mathrm{VI}$. as condições necessárias à formação do aluno no âmbito profissional;

VII. a contextualização dos conhecimentos gerados no ambiente de trabalho para a reformulação dos cursos;

VIII. a inclusão do aluno com necessidades específicas no mercado de trabalho.

$[\ldots]$
}

Com base nessas diretrizes legais, foi definida a seguinte proposta para o componente curricular Estágio Supervisionado II que compreende nas seguintes etapas: I) Reflexões Teóricas (Atividades Curriculares), II) Estágio na Escola - Observação e análise da realidade, atividades de coparticipação, docência compartilhada e regência de classe e III) Relatório final.

\subsection{Caracterização da escola pesquisada}

A Escola Estadual de Ensino Fundamental Domingos Perim é uma instituição pública de ensino fundamental II que atende alunos do $6^{\circ}$ ao $9^{\circ}$ ano. Está localizada na cidade de Venda Nova do Imigrante, no Espírito Santo. O presente relato diz respeito à prática de estágio desenvolvida nas aulas da disciplina de Língua Portuguesa em três turmas de $6^{\circ}$ ano do turno matutino.

As turmas, em geral, são formadas por alunos pré-adolescentes, entre 11 e 12 anos, que formam grupos de cerca de 26 a 28 alunos por sala. Em sua maioria, com os períodos de observação, coparticipação e regência, observamos que a professora regente ministrava atividades diferenciadas sobre leitura e interpretação de textos. Nesse período, pudemos observar também que os discentes 
apresentavam dificuldades básicas de escrita e de leitura, o que contribuía significativamente para a dificuldade de compreensão de enunciados de provas e atividades corriqueiras na sala de aula.

\section{Fundamentação teórica}

Segundo as pesquisadoras Selma Pimenta e Maria Socorro Lima (2012), na obra Estágio e docência, a finalidade do estágio é propiciar ao aluno uma aproximação com a realidade escolar. As autoras destacam ainda que:

[...] O estágio como componente curricular e eixo central nos cursos de formação de professores [...] apresenta os aspectos indispensáveis à construção do ser profissional docente no que se refere à construção da identidade, dos saberes e das posturas necessárias (PIMENTA; LIMA, 2012, p. 29).

Desse modo, como proferem as autoras, observando e convivendo com o professor por meio do estágio e construindo a nossa identidade docente, percebemos o quanto é importante relacionar os conhecimentos adquiridos na graduação com a prática vivenciada na escola. Vale ressaltar também que "[...] é pensando criticamente a prática de hoje ou de ontem que se pode melhorar a próxima prática" (FREIRE, 1996, p. 39). Assim, reafirmamos o quão necessário é a execução do estágio presencial, pois é nele que vivenciamos novas experiências, podendo analisá-las, investigá-las e interpretá-las, enxergando de maneira crítica a realidade escolar.

Partindo da nossa observação quanto à compreensão da competência de leitura pelos alunos, buscamos nos documentos oficiais o que se espera do aluno na construção do processo de leitura. Segundo os Parâmetros Curriculares Nacionais (PCNs):

\footnotetext{
A leitura é o processo no qual o leitor realiza um trabalho ativo de compreensão e interpretação do texto, a partir de seus objetivos, de seu conhecimento sobre o assunto, sobre 0 autor, de tudo o que sabe sobre a linguagem etc. Não se trata de extrair informação, decodificando letra por letra, palavra por palavra. Trata-se de uma atividade que implica estratégias de seleção, antecipação, inferência e verificação, sem as quais não é possível proficiência. É o uso desses procedimentos que possibilita controlar o que vai sendo lido, permitindo tomar decisões diante da dificuldade de compreensão, avançar na busca de esclarecimentos, validar no texto suposições feita (MEC, 1998, pp.69-70).
}

Observamos que a leitura é um processo de trabalho ativo do fazer docente, levando à abordagem de procedimentos e de estratégias de leitura como seleção, antecipação, inferência e verificação. Infelizmente, o que muitas vezes acontece é que o docente desenvolve somente o que está no livro didático, não possibilitando o aprofundamento desta competência leitora. Quando há o aprofundamento da leitura em sala de aula, como menciona o documento, possibilita-se ao aluno um 
aprofundamento do que vai ser lido e avançar na busca de conhecimento. Nesse sentido, a Base Nacional Curricular Comum (BNCC) nos aponta que:

\begin{abstract}
Ao longo do Ensino Fundamental - Anos Finais, os estudantes se deparam com desafios de maior complexidade, sobretudo devido à necessidade de se apropriarem das diferentes lógicas de organização dos conhecimentos relacionados às áreas. Tendo em vista essa maior especialização, é importante, nos vários componentes curriculares, retomar e ressignificar as aprendizagens do Ensino Fundamental - Anos Iniciais no contexto das diferentes áreas, visando ao aprofundamento e à ampliação de repertórios dos estudantes. Nesse sentido, também é importante fortalecer a autonomia desses adolescentes, oferecendo-lhes condições e ferramentas para acessar e interagir criticamente com diferentes conhecimentos e fontes de informação (BNCC, 2018, p. 60).
\end{abstract}

Compreendemos que, nesta etapa de ensino, os alunos são levados a ampliar seu repertório de leitura e compreensão de mundo a fim de interagir com os diferentes componentes curriculares que entrelaçam seu conhecimento. É importante destacar que a autonomia do estudante é fundamental para a compreensão do que se está lendo e compreendendo para que se faça sentido no seu aprendizado. Nesse sentido, citamos Isabel Solé (1998), pois a autora nos mostra o quanto é importante construir um leitor com autonomia, que compreende o que está lendo. Assim, a autora afirma que:

[...] o leitor constrói o significado do texto. [...] Isto não quer dizer que o texto em si mesmo não tenha sentido ou significado. [...] 0 significado que um escrito tem para o leitor não é uma tradução ou réplica do significado que o autor quis Ihe dar, mas uma construção que envolve o texto, os conhecimentos prévios do leitor que o aborda e seus objetivos (SOLÉ, 1998, p. 22).

Kleiman (2002) salienta que:

\begin{abstract}
A compreensão de um texto é um processo que se caracteriza pela utilização de conhecimento prévio: o leitor utiliza na leitura o que ele já sabe, o conhecimento adquirido ao longo de sua vida. É mediante a interação de diversos níveis de conhecimento, como o conhecimento lingüístico, o textual, o conhecimento de mundo, que o leitor consegue construir o sentido do texto. E porque o leitor utiliza justamente diversos níveis de conhecimento que interagem entre $\mathrm{si}$, a leitura é considerada um processo interativo. Pode-se dizer com segurança que sem 0 engajamento do conhecimento prévio do leitor não haverá compreensão (p. 13).
\end{abstract}

Para que haja uma compreensão leitora competente, é importante o conhecimento prévio, instigado pelo professor, fazendo levantamento de informações sobre o assunto que se pretende estudar. É também importante o conhecimento de mundo para que o aluno possa perceber o sentido do que se está lendo. Assim, o processo interativo se faz efetivo e a possibilidade de compreensão da leitura se faz autônoma.

É relevante pontuar que há leituras que nos permitem confrontarmos com textos novos e/ou com textos já lidos e, desse modo, constituir um novo texto e/ou novos textos, dando protagonismo e 
autonomia ao leitor dessa etapa de ensino. Acreditamos que as possibilidades são infinitas como menciona Rojo (2002, p. 3):

\begin{abstract}
Mais recentemente, a leitura é vista como um ato de se colocar em relação um discurso (texto) com outros discursos anteriores a ele, emaranhados nele e posteriores a ele, como possibilidades infinitas de réplica gerando novos discursos/textos. O discurso/texto é visto como conjunto de sentidos e apreciações de valor das pessoas e coisas do mundo, dependentes do lugar social do autor e do leitor e da situação de interação entre eles finalidades da leitura e da produção do texto, esfera social de comunicação em que 0 ato da leitura se dá. Nesta vertente teórica, capacidades discursivas e linguísticas estão crucialmente envolvidas.
\end{abstract}

Diante dessa breve colocação sobre leitura, das nossas percepções durante o período de observação e coparticipação, a nossa proposta pedagógica de ensino foi construir junto com os alunos a compreensão da leitura de trechos do livro "O diário de Anne Frank" de Anne Frank, buscando desenvolver sentido, apreciações de valores e, principalmente, ampliar a capacidade leitora do nosso aluno. Assim, desenvolvemos uma sequência didática sobre a leitura de trechos do diário aguçando nos alunos a leitura e a produção de escrita a partir do gênero diário.

Quanto à regência, para subsidiar o nosso trabalho em sala de aula, utilizamos a metodologia de ensino de Dolz e Schneuwly (2011) que, por meio de uma sequência didática, propõem uma estratégia que é válida tanto para produções orais quanto escritas. A sequência didática caracteriza-se por constituir "[...] uma sequência de módulos de ensino, organizados conjuntamente para melhorar uma determinada prática de linguagem" (DOLZ; SCHNEUWLY, 2011. p.43). Acreditamos que essa metodologia estimula a investigação sobre 0 assunto pelo aluno e valoriza a aprendizagem, uma vez que o coloca como protagonista de sua aprendizagem.

Além disso, as sequências didáticas "[...] instauram uma primeira relação entre um projeto de apropriação de uma prática de linguagem e os instrumentos que facilitam essa apropriação" (DOLZ; SCHNEUWLY, 2011. p.43). Por isso, utilizamos como instrumento metodológico a sequência didática para o ensino de gêneros, uma vez que facilita o aprendizado dos estudantes na medida em que segmenta o estudo em etapas, que de acordo com os autores acima citados, se dividem em: I apresentação da situação; II - primeira produção, III - módulos e IV - produção final. Conforme se expõe:

Na apresentação da situação constrói-se de uma situação de comunicação, apresenta-se um problema de comunicação e prepara-se os conteúdos do que será lido. A produção inicial é o momento em que os alunos elaboram suas hipóteses sobre o texto que será lido. As primeiras hipóteses auxiliarão na preparação dos módulos. São nos módulos que se trabalharão os conhecimentos prévios que apareceram nas atividades de pré-leitura. Nesse momento ainda pode ser estudado alguns conteúdos, de forma integrada, das diversas áreas do conhecimento (Matemática, Ciências, História etc.), com a língua materna. Por fim, são propostas, como produção final, novas atividades (pós-leitura) sobre o que foi lido. Essas tarefas precisam partir 
das mais simples para as mais complexas, preparando os alunos para uma nova leitura. Nessa etapa da atividade o professor tem a oportunidade de avaliar a sequência de uma forma geral (SILVA; MORAES, 2016, p. 7).

Dessa forma, apresentamos o gênero diário para os discentes e, ao final, eles tiveram que colocar em prática tudo o que fora aprendido. Pretendíamos, com a realização e aplicação da sequência didática sobre 0 gênero em questão, levar o estudante a perceber as peculiaridades e características constitutivas de um diário, bem como de um relato pessoal, além de estimulá-los ao aprimoramento da escrita e da leitura.

Como salienta Silva e Sousa $(2013$, p.13) a leitura, assim como a escrita, "[...] assume uma função de destaque nas atividades escolares, sociais e culturais. É a partir da leitura que construímos a nossa visão de mundo e nos constituímos como sujeitos sócio históricos no meio em que atuamos". Dessa maneira, entendemos que a leitura é o ato de compreender e de interpretar textos orais e escritos, de diversos tipos e gêneros textuais, de acordo com as intenções e objetivos.

\section{Descrição da experiência}

As experiências vivenciadas durante o estágio supervisionado nos aproximaram da realidade e nos fizeram questionar, pensar, repensar, observar e refletir sobre a educação e a prática docente. As primeiras semanas foram inteiramente de observação e análise, em que acompanhamos a docente em sala de aula para levantamento dos dados para futuros diagnósticos.

As atividades de coparticipação começaram com a iniciativa da professora em nos pedir para que ficássemos com a turma enquanto ela precisava se ausentar rapidamente, inclusive em momentos de prova. No decorrer das aulas, a docente passou a solicitar o nosso auxílio para realizar o tradicional "visto" nos cadernos dos alunos que haviam cumprido as atividades propostas. De forma gradativa, passamos a ajudá-la em diversas outras práticas, tais como realizar a chamada, tirar dúvidas dos alunos com dificuldade na realização de alguma atividade ou em entender algum ponto do conteúdo estudado, levar os alunos à biblioteca da escola a fim de realizarmos a leitura de textos.

O ponto máximo do estágio supervisionado ocorreu no período de regência, quando foi decidido, juntamente com a professora tutora, que lecionaríamos para duas turmas de sexto ano do turno matutino a respeito do gênero textual diário. $O$ trabalho com o gênero diário justifica-se pelo fato de que é um gênero discursivo que promove a reflexão individual, que possui linguagem simples, que preza pelas impressões pessoais e relatos, sem grandes preocupações literárias, o que aproxima o escritor e leitor da língua falada e escrita. Além disso, "[...] utilizar o diário como material didático é compreender sua 
riqueza, uma vez que este oferece uma dimensão do perfil social, histórico, político, cultural do momento em que foi escrito" (POZZANI; STEFFLER; BARBIERI, 2016, p. 8). Dessa forma, tínhamos como objetivo estimular os estudantes a produzirem textos expressivos, partindo de uma lembrança importante de sua vida.

O objetivo principal da sequência elaborada e aplicada para as turmas foi produzir 0 conhecimento dos alunos acerca do gênero diário, bem como estimulá-los ao desenvolvimento da escrita, da leitura e de sua narrativa, além de corroborar para que eles tivessem autonomia em suas próprias produções.

Iniciamos a regência instigando os alunos sobre o que conheciam sobre o gênero diário. Foram lançados questionamentos de reflexão sobre 0 assunto a fim de que, oralmente, expusessem suas experiências e saberes sobre a temática. Em um primeiro momento, instigamos os discentes a proferirem o que já sabiam sobre o gênero diário por meio de perguntas simples. Em seguida, trabalhamos o gênero diário, sua importância e função. Além disso, mostramos os elementos próprios desse tipo de gênero textual e, em seguida, realizamos uma atividade oral com o intuito de estimular o discurso dos alunos e fazer com que recordassem de fatos importantes de suas vidas que mereceriam destaque.

Em um segundo momento, trabalhamos especificadamente com o livro "O diário de Anne Frank", estruturado em forma de diário em que a personagem central faz relatos pessoais e emocionantes sobre a tensão que a família judia Frank sofreu durante a segunda Guerra Mundial. Realizamos a leitura de algumas páginas da obra e contextualizamos a obra. Adiante, desenvolvemos uma análise do livro observando as características e estruturação do gênero diário.

Após discussão e apropriação dos instrumentos de linguagem característicos desse gênero, solicitamos aos discentes que desenvolvessem uma página de diário. 0 objetivo foi relatar um fato marcante ou diferente que eles tenham vivenciado recentemente ou no passado. Ao findar da atividade, os textos foram expostos em um "varal diário", dentro da própria sala e, então, os estudantes tiveram a oportunidade de ler a produção dos outros colegas de classe, compartilhando experiências enriquecedoras.

\section{Avaliação dos resultados}

Os alunos do sexto ano, ao realizar a atividade descrita acima, cumpriram uma tarefa que exigiu deles a capacidade de escrita, de síntese de alguma história de sua vida e a aplicação correta dos elementos característicos do gênero estudado em um texto escrito. À vista disso, a aproximação com o gênero diário corrobora para que o estudante, em um diálogo incessante entre ele (escritor) e leitor, 
torne-se protagonista e narrador de sua escrita, bem como propicia uma estreita relação entre a interação do sujeito com o mundo à sua volta. Por meio dessa atividade, ainda foi possível trabalhar a capacidade de leitura, escrita e produção. Acreditamos que, ao findar das aulas, os alunos tenham de fato aprendido sobre o que é o gênero diário, a sua importância e quais as suas características constitutivas.

Com o intuito de obter um retorno dos discentes sobre a sequência de aulas por nós organizadas a respeito do gênero diário, realizamos, de maneira breve, a aplicação de uma pesquisa simples por meio de um pequeno papel contendo cinco emojis (desenhos) representando cinco sentimentos, a saber: 1. Detestei, 2. Não gostei, 3. Indiferente, 4. Gostei, 5. Adorei. Os estudantes receberam o comando de circular ou colorir qual emoji melhor representava a sua satisfação com as aulas dadas. Como resultado, cerca de $90 \%$ das respostas foram relacionadas à opção "adorei".

\section{Algumas considerações}

Consideramos o período de estágio supervisionado como uma experiência positiva, enriquecedora e desafiadora. Percebemos que os alunos compreenderam o conteúdo ensinado, o que se pode verificar através das produções escritas realizadas por eles em sala de aula e pela avaliação aplicada a respeito de nosso desempenho como professoras-estagiárias.

Além disso, por meio da experiência de ensino realizada, consideramos que a atividade desenvolvida com os discentes contribuiu para o desenvolvimento de sua escrita e leitura, pois o relato que escreveram demandava deles uma capacidade de síntese, atenção aos fatos narrados e coerência no que estava sendo dito. Isto é, a proposta de trabalho viabilizou o aprimoramento da língua.

Em suma, o estágio propiciou uma aproximação significativa com a prática docente, visto que, pela observação, pela coparticipação e, principalmente, pela regência em sala de aula, aumentamos nossa percepção quanto aos métodos de ensino eficazes, contextualizados e que realmente tem significado para o aluno. Além disso, a nossa aproximação com o estudante serviu para reafirmar nosso pensamento de que os docentes não formam apenas estudantes e, sim, sujeitos para a vida e para a cidadania.

\section{Referências}

BRASIL. Parâmetros curriculares nacionais: terceiro e quarto ciclos do ensino fundamental: língua portuguesa. Secretaria de Educação Fundamental. Brasília: MEC/SEF, 1998. 
. Lei $n^{0} 11.788$, de 25 de setembro de 2008. Dispõe sobre o estágio de estudantes e dá outras providências. Diário Oficial da União, Brasília, 26 de set. 2008.

\begin{tabular}{l} 
Base Nacional Comum Curricular (BNCC). Educação é a Base. Brasília, \\
\hline MEC/CONSED/UNDIME, 2018.
\end{tabular}

Ministério da Educação. Resolução CNE/CP $n^{\circ}$ 2, de 20 de dezembro. Define as Diretrizes Curriculares Nacionais para a Formação Inicial de Professores para a Educação Básica e institui a Base Nacional Comum para a Formação Inicial de Professores da Educação Básica (BNC-Formação). Brasília, DF, 2019.

DOLZ, J; SCHNEUWLY, B. Gêneros orais e escritos na escola. 3. ed. Campinas, São Paulo: Mercado de Letras, 2011.

FRANK, A. O diário de Anne Frank. 54 ed. Rio de Janeiro: Record, 2015.

FREIRE, P. Pedagogia da autonomia: saberes necessários à prática educativa. São Paulo: Editora Paz e Terra, 1996.

INSTITUTO FEDERAL DO ESPÍRITO SANTO. Resolução do Conselho Superior $n^{\circ}$ 58/2018, de 17 de dezembro de 2018, que regulamenta os estágios dos alunos da Educação Profissional Técnica de Nível Médio e da Educação Superior do Instituto Federal de Educação, Ciência e Tecnologia do Espírito Santo (Ifes), Vitória - ES, 2018.

KLEIMAN, A. Texto e Leitor: Aspectos Cognitivos da Leitura. 8ª Ed. Campinas, SP: Pontes, 2002.

PIMENTA, S. G.; LIMA, M. S. L. Estágio e Docência. 7. ed. São Paulo: Cortez Editora, 2012. 296 p.

POZZANI, G., M.; STEFFLER, J., BARBIERI, C. O gênero diário pessoal: contexto e interdisciplinaridade no estudo da obra Diário de Anne Frank. Cadernos PDE. v.1. 2016. Disponível em: <http://www.diaadiaeducacao.pr.gov.br/portals/cadernospde/pdebusca/producoes_pde/2016/2 016_artigo_port_unespar-paranavai_gracianamartelozopozzani.pdf>. Acesso em: 10 mai. 2019.

ROJO, R. H. R., A concepção de leitor e produtor de textos nos PCNs: "Ler é melhor que estudar". In FREITAS, M. T. A.; COSTA, S. R. (Orgs.). Leitura e Escrita na Formação de Professores, SP: Musa/UFJF/INEP-COMPED, 2002. p. 31-52

SILVA, A.; SIMÕES, A. C. Práticas de leitura em sala de aula: o uso de filmes e demais produções cinematográficas em aulas de Língua Portuguesa. Práticas de Linguagem, v. 1, n. 2, p.52-59, jul./dez. 2011.

SILVA, F. C.; MORAES, P. P. Estratégias de leitura por sequência didática: o gênero poema. Anais do X Simpósio Linguagens e Identidades da/na Amazônia Sul-Ocidental, n. 1, 2016.

SOLÉ, I. Estratégias de Leitura. 6. ed. Porto Alegre: Artmed, 1998.

Data de submissão: 28/07/2020. Data de aprovação: 27/10/2020. 